

\title{
Redefining Undergraduate Success at Oregon State University
}

\section{Report from Spring 2014 Invitational Workshop}

October 9, 2014

Rapporteurs: Julie Risien, John H. Falk and Martin Storksdieck

With contributions and reviews from Larry Flick, Daniel Newhart, Susie Brubaker-Cole, Kevin Ahern, Salvador Castillo, and Jana Bouwma-Gearhart.

\section{Summary}

On April 7, 2014 the Center for Research on Lifelong STEM Learning and the Office of the Associate Provost for Academic Success and Engagement ${ }^{1}$ launched the Undergraduate Success Initiative with an invitational workshop entitled Redefining Undergraduate Success. A small planning team convened a group of 32 faculty and administrators with a wide array of perspectives and experiences. The goal of the workshop was to define "success" or "derived benefits" of an undergraduate OSU experience, a definition that will form the foundation for a comprehensive framework that ties student outcomes with OSU facilitated experiences within and outside of classrooms and laboratories. Ultimately, this report will serve as the basis for a well-reasoned and supported research agenda that will directly contribute to understanding and measurably improving student success. The research agenda will be part of an overarching initiative to reform undergraduate education at OSU through design-based implementation of evidence-based educational and learning practices at OSU.

Suggested citation: Risien, J., Falk, J.H., Storksdieck, M. (Rapporteurs). Redefining Undergraduate Success at Oregon State University: Report from Spring 2014 Invitational Workshop. Corvallis, OR: Oregon State University, Center for Research on Lifelong STEM Learning. October 9, 2014.

\footnotetext{
${ }^{1}$ Dr. Susie Brubaker-Cole held this position at the time of the workshop and has since transitions into the role Vice Provost for Student Affairs, as such primary administrative partnership for this initiative sits with the Division of
} 


\section{Contents}



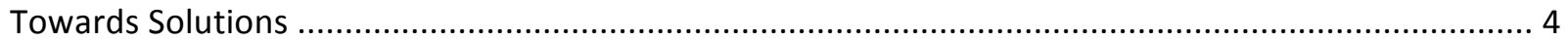

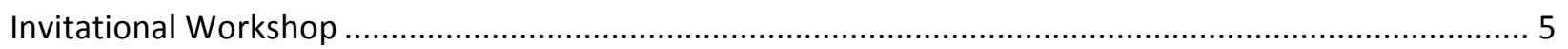

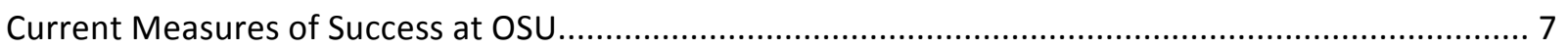

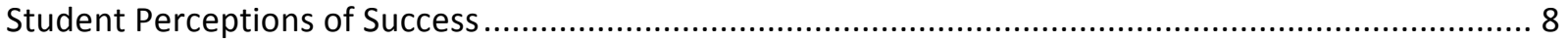

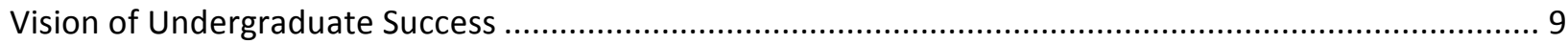

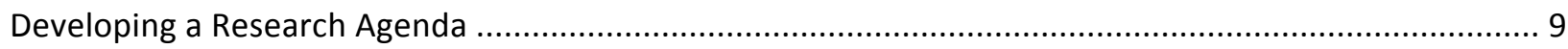

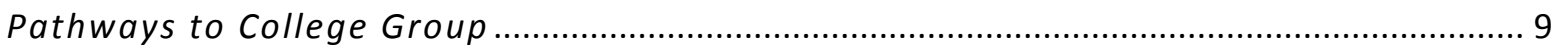

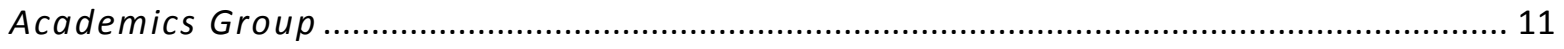



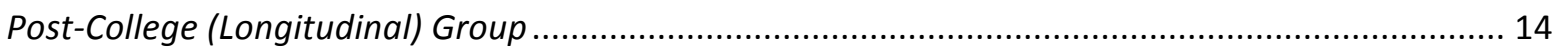

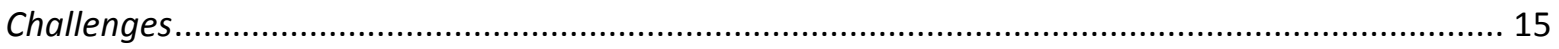

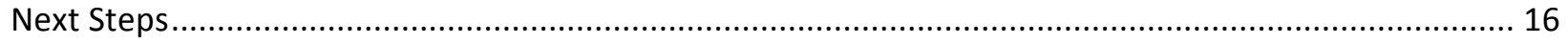

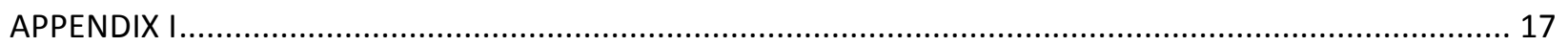

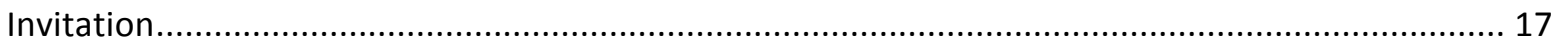

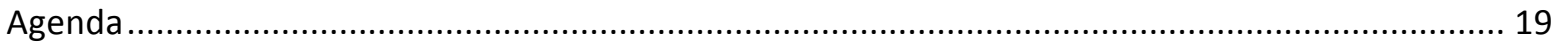

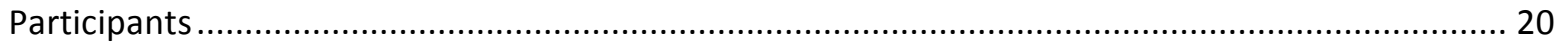




\section{Introduction}

The world of undergraduate education is rapidly changing. There is increasing demand for institutional accountability by students, parents, policy makers and the public at large. Enrollment rates are flattening at a time when more undergraduate options are available; parents and incoming students are paying more attention to cost-benefit ratio of the undergraduate learning experience, and competition for students is increasing. The trend toward commoditization of undergraduate education, and technological advances that enable online degrees are challenging traditional residential institutions to provide evidence of added value for the entire undergraduate experience they provide. Simultaneously, political pressure is mounting to move higher education away from "seat time" (or accumulated credits) and towards a competency-based system, posing the challenge of exactly what competencies are valued and should be assessed as the basis for granting baccalaureate degrees or to assess the effectiveness of the system (the university) that provides the education towards such competencies. Now is the time for Oregon State University to proactively define what a successful undergraduate experience at a researchintense comprehensive university entails, determine the curricular and co-curricular experiences that OSU may provide towards student success, develop a system of evidence-based continued improvement and enhancements of these experiences, and seek evidence of the added value OSU offers its students in the short and long run.

The quality and value of undergraduate education has recently received considerable national media attention and the topic has attracted the attention of policy makers, parents, and current and prospective students alike. There appears to be a growing public consensus that higher education is in crisis, although stakeholders disagree on both the nature and causes of the crisis. There are undeniable challenges: states continue to reduce funding; tuition and fees are at all-time highs and continue to rise significantly faster than the rate of inflation; consequently the accumulated student debt in the US has surpassed a staggering \$1 Trillion; graduation rates are stagnant or declining (especially for underserved populations); and post-college employment is all too often elusive with $53 \%$ of recent college graduates jobless or underemployed. ${ }^{2}$ For perhaps the first time, prominent in the media are articles and discussions questioning the value of a 4-year baccalaureate degree, and among scholars discussions are heated as to what kind of post-secondary degree or certificate might serve what learner the best. While most well informed observers currently conclude that a post-secondary degree is well worth the investment, higher education institutions are challenged to find sufficient evidence, beyond metrics of long-term salary gains, of value gained through the undergraduate experience. Institutions of higher learning need to find ways to deliver the highest quality, yet cost-effective undergraduate experiences and demonstrate a total value package that is superior to current competitors and new, technology enabled mechanisms to earn BS/BA degrees.

\footnotetext{
${ }^{2} \mathrm{~A}$ full article referencing underemployed and joblessness among college graduates can be found here http://www.theatlantic.com/business/archive/2012/04/53-of-recent-college-grads-are-jobless-or-underemployedhow/256237/.
} 


\section{Towards Solutions}

Several national efforts ${ }^{3}$ are underway to address issues in Higher Education as they become a prominent national priority. Although attention has been focused on the failings of for-profit universities accused of issuing questionable degrees, fostering narrow skill sets and charging too much, scrutiny is shifting to public institutions as well. Failure to adequately conceptualize and measure the total value added by the university undergraduate experience will deprive consumers (students and, to a degree, their caregivers who often support them) the opportunity to make informed decisions when choosing an educational path. Universities such as OSU seek to optimize student outcomes by offering far more than academics: co-curricular activities on and off campus can play a significant and supportive role in the total education of an undergraduate student, but such activities are most impactful when they are optimally aligned with overarching educational goals. The challenge is to overcome current pressures that stem from the need to contain cost while improving quality by understanding the value of students' entire experience, articulating the total experience offered and convey how it translates into a stronger vision of undergraduate success. All the while seeking and continually adapting to productive evidence-based feedback on how we serve our students during the critical final formative years of their education.

Universities already collect a range of data on recruitment, retention, under-represented enrollments, international enrollments, and college success correlated with pre-college grades and standardized tests; OSU is no exception. These metrics do not tell the whole story of undergraduate education, though; they fail to tell us how our graduates participate in society, derive financial security and personal fulfillment and how those factors are related to the specifics of their undergraduate experience. Moreover, they fail to provide actionable information that help shape and optimize those on and off campus student experiences that are most likely to lead to success during and post college.

If OSU is to fully achieve our Land Grant and university mission we need to know how to attract the best student body for the type of university we represent, justify student financial and time investments, and learn how to improve and evolve in a rapidly changing undergraduate education environment. OSU investigations on comprehensive student success can separate us from the competition by providing clarity and evidence about what is unique and valuable about an OSU undergraduate experience. In fact, other colleges and universities are beginning with similar efforts adding urgency to this task and rendering it a new norm of reflective practice in higher education.

In 2014, the Center for Research on Lifelong STEM Learning and the Associate Provost for Academic Success and Engagement established an undergraduate success initiative with these aims in mind.

\footnotetext{
${ }^{3}$ Association of American Universities, AAC\&U, Association of Public Land Grant Universities, Sloan Foundation, Lumia Foundations, The National Science Foundation and the National Academies of Science are only some of the organizations trying to remedy the crisis in higher education.
} 


\section{Invitational Workshop}

On April 7, 2014 the Center for Research on Lifelong STEM Learning and the Office of the Associate Provost for Academic Success and Engagement launched the Undergraduate Success Initiative with an invitational workshop entitled Redefining Undergraduate Success. A small planning team convened a group of 32 faculty and administrators with a wide array of perspectives and experiences. The goal of the workshop was to define proactively and specifically what we mean by a successful OSU undergraduate experience. Definitions of "success" or "derived benefits" of an undergraduate OSU experience will form the foundation for a comprehensive framework (to be developed in the next phase of the project) that ties student outcomes with OSU facilitated experiences within and outside of classrooms and laboratories. Ultimately, this report will serve as the basis for a well-reasoned and supported research agenda that will directly contribute to understanding and measurably improving student success. The research agenda will build on the foundation of what is known about student success nationally and become part of an overarching initiative to reform undergraduate education at OSU through design-based implementation of evidence-based educational and learning practices at OSU.

The workshop was designed to address the first two initiative objectives.

1. Begin to operationally define key components of undergraduate success to which OSU aspires or ought to aspire. These components of undergraduate success will include traditional measures such as disciplinary knowledge and skills, graduation rates, initial employment rates and salaries, or life earnings. However, in order to prepare students for success in life, career and society, outcomes associated with $21^{\text {st }}$ Century skills need to be considered. These include thinking and decision making skills such as creativity, innovation, non-routine problem solving, critical thinking; personal skills such as persistence, reflection, self-regulation, etc.; and social/interpersonal skills like collaborative ability, communication skills, empathy, and tolerance. Additional civic engagement outcomes include attitudes, identities, mindfulness and social responsibility. Broader holistic outcomes that capture a graduate's long-term growth might complement the economic measure of life earnings and include "happiness" and life satisfaction.

2. Flowing from these parameters of student success, develop an initial set of key indicators for agreed-upon components of undergraduate success, and derive research questions that link these components with ways in which student experiences (while at OSU) may impact student outcomes variables. In other words, identify which investigations are needed to understand current realities, current student outcomes and how they relate to university practices and products.

Later stages of this initiative will focus on a third objective.

3. Organize the development of a long-term research program at OSU that directly contributes to understanding how to measure and track long-term students success, including key short-term and long-term indicators and metrics. Measures and metrics will be designed to provide tangible benchmarks enabling the OSU community to empirically judge both the efficacy of its 
current efforts as well as guide the design of additional efforts needed to support comprehensive student success outcomes. They will also include faculty and instructional staff awareness of broader outcomes of student success, as well as measures for their willingness to contribute to an extended set of criteria for student success.

Workshop participants were asked to think expansively and holistically about success to include ideas associated with the following concepts

- Values, attitudes and dispositions

- Civic engagement and participation in democracy

- Contributions to and participation in communities of place

- Commitment to lifelong learning

- Skills and abilities

- Scientific, cultural, and environmental literacy

- 21st Century Skills (e.g., collaboration, communication, technology, creativity, social responsibility)

- Career and professional

- Contribution to chosen professional field (related or not to college major)

- Contribution to and participation in communities of practice

- Contribution to the economy, business, technology, and innovation

- Wellness

○ Health

- Happiness / satisfaction

- Financial security

- And additional ideas that may surface through the day's discussion.



Participants were also asked to think expansively about the factors that contribute to success, including but not limited to:

- What kind of preparation do OSU students have?

- What are students' expectations for enrolling at OSU?

- Who does and who doesn't apply for admission at OSU?

- Where do students come from (high school, transfer from community college, transfer from other 4-year institution)

- What is the students' in-classroom experience?
- What types of co-curricular and freechoice learning experiences are students engaging in?

- What are students' life experiences outside the university or classrooms that are not associated with specific "learning" activities?

- What do students do immediately upon graduation?

- Where does the OSU responsibility for its undergraduate students begin and where does it end? 
Participants answered the call by thinking "big"; they successfully avoided getting bogged down in methodology, data and other complexities. The workshop invitation, agenda, list of planning team members and participants are included as Appendix I.

\section{Current Measures of Success at OSU}

Like most universities, OSU is engaged in various efforts to improve, monitor and measure outcomes and success of graduates. Oregon University System's partnership in the Association of American Colleges and Universities (AAC\&U) Liberal Education and America's Promise (LEAP) Initiative ${ }^{4}$ is one effort toward improvement of the undergraduate experience and undergraduate success. LEAP includes a national advocacy, campus action, and a research initiative that champions the importance of a twenty-first century liberal education - for individuals and for a nation dependent on economic creativity and democratic vitality. In 2010 the OSU Faculty Senate approved a set of Learning Goals for Graduates (LGGs) ${ }^{5}$ unique to OSU. These goals promote the following competencies:

1. Competency and Knowledge in Multiple Fields

2. Critical Thinking

3. Pluralism and Cultural Legacies

4. Collaboration

5. Social Responsibility and Sustainability

6. Communication

7. Self-Awareness and Life-Long Learning

While these represent important steps towards graduating well-rounded and successful students, they are not widely integrated into academics and campus activities. There are metrics associated with the LGGs; however, at the time of this report the institution lacked specific mechanisms for monitoring the extent to which goals are met.

OSU also participates in a suite of both internal and external monitoring and measurement efforts. Internal measurement schemes include establishing and monitoring strategic planning metrics, an undergraduate exit survey (since 2013), and the National Survey of Student Engagement (NSSE) ${ }^{6}$. Through NSSE, the OSU Office of Student Affairs Research annually collects information about student participation in programs and activities that OSU provides for student learning and personal development. The results provide an estimate of how undergraduates spend their time and what they gain from attending college. The workshop planning team considers NSSE a vastly underutilized information source. External measurement efforts are compliance-based and include the federal government Integrated Postsecondary Education Data System and monitoring related to institutional accreditation and the state compact. At this point, the various data sources that are already available at

\footnotetext{
${ }^{4}$ More Information about OUS and LEAP can be found here https://www.aacu.org/leap/oregon_initiative.cfm.

${ }^{5}$ The complete list of LGGS can be found here http://oregonstate.edu/leadership/provost/initiatives/learninggoals-for-graduates.

${ }^{6}$ More Information about NSSE can be found here http://nsse.iub.edu/html/about.cfm.
} 
OSU are not yet integrated to capture simultaneously student experiences across formal, co-curricular, and private experiences.

\section{Student Perceptions of Success}

Workshop participants were asked to draw on their knowledge and assumptions of students' expectations of a successful undergraduate experience. Participants' collective experience and assumptions are included in the below paragraphs. [A formal survey with students of student perceptions of success is envisioned].

Many students have underdeveloped and sometimes uninformed expectations of success. Student perceptions of success are often shaped by that of their parents and peers and messages from their chosen university. There is a tendency for students to believe in the current basic university model of accumulated credit hours: that if they show up, study, stay enrolled, keep decent grades and graduate they are successful. Many students do not express expectations with regard to quality of teaching and learning while others assert expectations of teaching not necessarily aligned with high quality or learning gains. Students clearly expect that success at a given institution will include transparent expectations set be educators and administrators, ease of system navigation, and programs that are delivered with the use of technology and media.

Life experience and professional training and preparation were the two dominant themes of student expectations that emerged during the workshop; both included a strong emphasis on relationship building. It is presumed that achieving the "university experience" through building a strong social network, participating in university life and co-curricular activities, practicing autonomy, developing adult competencies, and "having fun" are high priorities for students ${ }^{7}$. Also a priority is receiving the preparation and training needed for a quick entry into a career or further education through professional experiences such as internships,

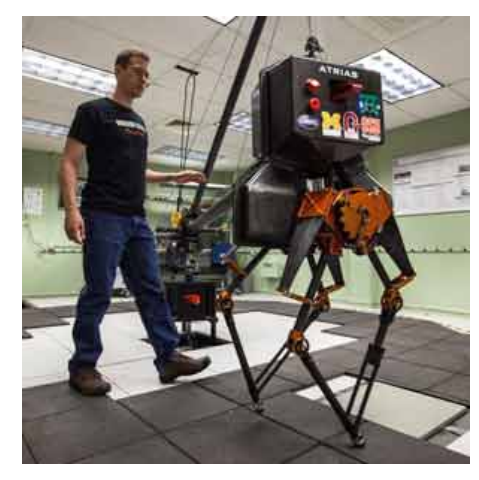
undergraduate research, opportunities to build professional relationships, and access to mentors and leaders in their field of interest; these are all seen as pipelines to near-term employment.

It is important to note that OSU's student body is not homogeneous, a growing percentage of students differ from historically predominant ages, races, nationalities and/or socio-economic status ${ }^{8}$. Less is known about non-traditional students; however they are arriving at the university with a different suite

\footnotetext{
7 The latter - "having fun" - is a factor that merits further investigation, in part because this criterion is of considerable importance to late adolescents and young adults, but can express itself in productive or destructive ways. Helping students define "fun" in ways that do not distract from academic success might be seen as an important obligation of the university

${ }^{8}$ In 2014 OSU's enrollment of minority students exceeded $20 \%$ and that of undergraduates over the age of 25 exceeded $16 \%$. Enrollment demographics summaries can be found at http://oregonstate.edu/admin/aa/ir/enrollmentdemographic-reports\#enroll-sum.
} 
of experiences and are likely to have some different expectations and needs associated with undergraduate success ${ }^{9}$.

\section{Vision of Undergraduate Success}

The below vision of undergraduate success is the result of discussion during the April 7, 2014 workshop.

OSU graduates are highly adaptable and across their life are able to adjust to fast rates of change and technological advances. They are resilient in the context of economic and social flux. They possess core competence and practical experience in a professional field that allows them continued success in their careers. They are skilled and practiced at understanding and connecting across differences of discipline, background, identity, ability, race, ethnicity, and nationality, and they comfortably embrace the richness that diversity can bestow in both their personal and professional lives and endeavors. They are capable of creating successful lives, are lifelong learners and continually seek experiences that challenge their minds and that contribute to continued competence and fulfillment in their personal, civic and professional lives.

\section{Developing a Research Agenda}

Workshop participants self-selected into four groups to identify key questions that ultimately serve to document the degree to which OSU is meeting the aspirational definition of success established during the first half of the workshop. The questions do not indicate the state of knowledge, but merely reflect the types of concerns, expressed as questions, that ought to guide a research agenda and programmatic needs as OSU addresses student success in a comprehensive way. The results are limited by the time available for group discussion and synthesis and will need refinement in future phases of the initiative.

\section{Pathways to College Group}

This group explored the relationship between our aspirational vision of success and the experiences and preparations current and expected future students are bringing to their undergraduate endeavors. The results focus on college readiness, student selection, understanding potential future students and effectively communicating with them. The group generated the following questions that could guide a research agenda:

1. What is college readiness and what do we expect of an OSU-ready student?

a. Is there a discrepancy between students' ideas about college readiness and what it ultimately takes to succeed as an undergraduate student? [The group opined that existing college readiness measures might be ineffective in measuring "readiness" when this is not merely understood as the capability to succeed academically in freshman

\footnotetext{
${ }^{9}$ Workshop participants did not have time to adequately explore the similarities and differences of the various categories of students comprising the current and future OSU student-body.
} 
classes, but is more comprehensively seen as an overarching ability to see oneself as a university student and act accordingly in and out of formal instruction.]

b. What measures could capture a more comprehensive meaning of "college readiness" that research suggests more accurately predicts college success? ${ }^{10}$

2. What do incoming students know about the full suite of post-secondary options available to them?

a. What are the academic, attitudinal, social, self-regulatory, etc. expectations for each of these options? Which dispositions best fit the different options?

b. Where does OSU fit in the overall constellation of post-secondary pathways to success? [Is OSU the right choice at the time? Would another 4-year institution be a better fit? Should students first attend a community college? If so, should they aim to complete the community college degree or transfer as quickly as possible? Etc.]

3. What messages are students getting that suggest that they are or are not ready for college, and how do those messages compare with the perceptions of university faculty and the expectations of admissions offices?

a. What message(s) does the college application process send to prospective students?

b. Do these messages relate to being a student at a major comprehensive land- and seagrant public university in a meaningful way?

c. What mechanisms should be put in place to inform future students, caregivers and other mentors, schoolteachers and guidance counselors about realistic expectations for college readiness?

4. What mechanisms are used to select students and how well are they working?

5. Which communities do OSU students come from?

a. How connected or removed are these communities from education norms and OSU'S aspirations?

b. Do communities that students come from instill certain norms associated with success in college and how do they relate to OSU as it is and as it aspires to be?

6. How do we engage each of those communities to facilitate success?

7. What actions make the campus more familiar or comfortable for students from different communities?

a. What are the most effective ways to inform potential students and families about what a college education can and cannot provide? How does this mesh with new or planned federal requirements to fully inform students about their prospective college experience?

8. Why do students seek a college education?

a. What motivates students to seek a college education? To what degree are their motivations shaped by cultural or community norms, peers, advisors and mentors or

\footnotetext{
${ }^{10}$ Note that a mix of IQ and standardized tests (long term success, an indicator of intelligence) and high school GPA (short-term success, an indicator of self-regulation). Comprehensive "college readiness" may include dispositional and identity-related measures that expose sense of belonging, connectedness, and "grit" which may be indicators of retention or graduation.
} 
other external factors, and to what degree are they motivated by student interests, career goals, notions of possible selves and other internal factors?

b. What do students hope to take from their education and college experience? Do their expectations for themselves align with those of the university?

c. How does OSU provide mentoring and coaching that aligns student and institutional goals over the first year of the college experience?

9. What do university faculty members know about incoming students? What are their attitudes towards incoming students?

10. What should university faculty members know about incoming students? What are productive frames of mind or attitudes and dispositions towards incoming students?

11. How are we serving the communities that feed the OSU student body? How, in turn are graduates serving the communities from which they came?

\section{Academics Group}

This group worked to identify questions related to academic activities students engage in that best contribute to our aspirational vision of success. The group identified some essential outcomes that can be related to academic endeavors and our aspirational vision of success, and generated the following list of questions that merit further investigations:

1. In what way does the OSU undergraduate experience influence students' academic learning outcomes (within and across disciplines)? [What objective and external measures of student success should the university put in place to monitor its ability for creating academically wellprepared students who can succeed in their chosen field of work? Should these data be collected for all students (as individual learning diagnostics) or collected from a representative sample of students?]

2. How does the OSU undergraduate experience influence essential student outcomes outside of disciplinary knowledge and skills, such as emotional development, reflectivity, open mindedness, empathy, self-efficacy, self-regulation, perseverance and grit, metacognition of their own knowledge and how knowledge is constructed?

3. How do we best support an OSU undergraduate experience that optimizes towards disciplinary and essential student outcomes?

4. Do we purposefully guide students in expanding their horizons and identify the best pathway to meet their long-term goals? [Which may mean, at least for a small fraction of students, not to be graduating from OSU]. What mechanisms are in place to assist students with orderly, efficient, and meaningful transition into other pathways toward success?

5. How does an institution and its educators decide upon common goals and learning outcomes and institutionalize practices that support them?

a. What encourages or enables faculty to create curriculum, instruction, or other experiences that foster academic and essential outcomes?

b. What are faculty perspectives on the nature of knowledge and skills and how they can be taught and learned? 
c. What factors predict or impact cohesive pedagogical practices within and across disciplinary groups or units? How can we better align student learning across individual academic units?

d. How do we develop an ecosystem that supports teaching and learning towards essential outcomes inside and outside of classrooms? What can OSU do to attend to out-ofclassroom factors known to impact academic performance? How to we integrate these known factors into a comprehensive system for student success?

e. What can we learn from organizational successes at other institutions and at OSU about connecting opportunities to learn in academic and non-academic environments?

f. How do we ensure students' critical thinking skills and knowledge are supported through formal instruction and informal experiences?

6. What is the value (per dollar) of academic experiences? Should we, and if, how do we measure this? Can we increase that at OSU?

7. Who is the system not working for and why? Which students are not succeeding within the system and why?

a. What are early quantitative indicators for students at-risk of failing classes within a chosen STEM major, dropping out altogether, or leaving OSU for another institution?

b. What are evidence-based interventions to support at-risk OSU students that are likely to work within the OSU context?

8. To what degree does teaching faculty satisfaction correlate with student success? Are there ways to utilize potential increases in faculty satisfaction as intrinsic motivators for using evidence-based teaching, coaching and mentoring practices?

9. What is the role of instructional faculty versus research faculty in instruction and how does the move away from tenured faculty for instruction impact the quality of what is taught, student satisfaction with their OSU experience, and student academic success?

10. How is technology improving/changing the educational experience and in what ways does OSU need to adapt to optimize success?

\section{Co-Curricular (out of the classroom) Group}

This group focused on questions that examine how co-curricular or outside of the classroom activities and factors affect student success. Students participate in a variety of informal and organized activities during their time at OSU that can either support the vision of their success, or serve as a barrier and distractor for success. It is certainly acknowledged that co-

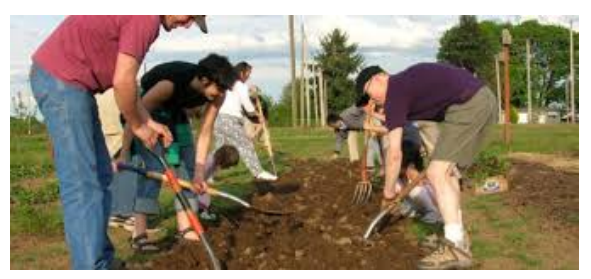
curricular activities can be highly supportive of skill, knowledge and character development of students, and those activities ought to be nurtured, encouraged, supported and integrated into the overall learning trajectory of a student, while not distracting or diverting student attention away from core academic pursuits. Other co-curricular activities and behaviors might put students at higher risk of under-performance and failure and should be discouraged. OSU is beginning to collect benchmark 
participation data for the co-curricular activities in which OSU students tend to engage ${ }^{11}$. Utilizing such benchmark measures for the current breadth of activities, participation levels, and student and institutional assessment models in order to link academic and non-academic life of OSU students would provide a powerful mechanism to align student experiences towards a common goal. Building on existing benchmarks, additional data needs can be filled towards developing a conceptual framework for comparison, support, integration and assessment of positive student activities. The group added the following questions towards this purpose:

1. How do you raise the level of challenge in a co-curricular learning environment in ways that aim at supplementing academic pursuits, and how can those be better integrated with curricular learning activities and outcomes?

2. How do outcomes compare when a student has many co-curricular engagements or goes deep in one area of co-curricular involvement over a longer period of time with those students who have limited or no co-curricular experiences?

a. To what degree does the nature of the co-curricular activity influence the outcomes?

b. What are the trade-offs between academic knowledge across a broad set of disciplines versus skill and deep-knowledge development in a narrow discipline or topic? What role can co-curricular activities play in providing a better balance between developing a broad knowledge base in many areas of academic pursuit, and gaining skills and actionable knowledge in a narrow range of disciplines or topics?

c. What is the relative contribution of structured co-curricular activities, and unstructured, more incidental experiences? What are the contributions of experiences initiated outside of OSU by students or entities in the communities surrounding campuses?

d. How does co-curricular learning within a community structure compare to co-curricular learning in a more individual mode and how can that inform modes of delivery and support for or investment in co-curricular activities?

3. Are there differences in the characteristics, timing, and contexts of participants vs. nonparticipants of co-curricular activities?

a. If participation in "productive" and "educationally supportive" co-curricular activities (and not all are) is benefiting students in general, how can students currently not engaged in those be better included?

b. How does participation in co-curricular experiences vary as function of student dimensions such as age, gender, race/ethnicity, socio-economic status, nationality and residential vs. commuter status?

4. Who are the mentors, role models and peers primarily associated with co-curricular activities? What are their roles and how might their roles be augmented to better support student success?

\footnotetext{
${ }^{11}$ OSU also conducts measures associated with the National Survey of Student Engagement, Multi-Institutional
} Study of Leadership, Educational Benchmarking Inc. assessments, and the National College Health Assessment. 
5. How can what is known about the differences between work-related and more intellectual or leisure-oriented co-curricular experiences guide the development and support of OSU cocurricular activities to better support student success?

\section{Post-College (Longitudinal) Group}

This group worked to identify questions and possible approaches that relate to achievement of individually and institutionally defined success through longitudinal studies. In addition to articulating elements of the aspirational vision of success into potential research questions, this group also identified some questions about methods to be considered during the next phase of this initiative:

1. To what degree do OSU graduates experience personal, civic and professional fulfillment at various times after graduation?

2. To what degree are OSU students who do not graduate successful in pursuing careers or alternative post-secondary education through a variety of pathways?

3. How adaptive, resilient, mindful, conscientious and persistent are OSU graduates and to what degree can those characteristics be attributed to academic and/or co-curricular experiences at OSU?

4. To what degree do OSU graduates demonstrate professional level competence in their chosen field/discipline, and to what degree did their OSU undergraduate experience contribute to their (ability to develop) professional competence?

5. How do OSU graduates perform with respect to understanding and promoting connection in a context of rich diversity? How tolerant, empathetic, civic-minded are they?

6. To what degree do OSU graduates feel prepared to make decisions that are aligned with their beliefs, values, norms and aspirations? How does this ability develop over time after graduation?

7. To what degree do OSU graduates contribute creative and innovative solutions to major problems and challenges in their professional, personal and civic lives?

8. How do OSU alumni contribute/give back to OSU (through service and financial support), and to what degree does this indicate post-graduation success in life, work, and satisfaction with the degree to which OSU helped them in their success?

9. What are OSU graduate incomes as compared to their peer groups, and controlled for by chosen fields of profession? How does relative income correlate (or not) with happiness and satisfaction?

10. Which elements of the student experience are believed by alumni as being most valuable to their future lives at the time of graduation and at points in time after graduation?

11. To what degree has OSU fostered in students curiosity and a love for lifelong learning and personal and professional growth, and what part of the overall OSU experience contributed significantly to these traits? 
During group discussions some questions about methods arose. They are listed here for consideration in the next phase of this initiative.

1. Which existing measures can be used or modified to understand if OSU graduates are achieving success according to our aspirational definition?

2. How can we use employer perceptions to better understand success of graduates?

3. Which elements of success are best measured through survey or self-reporting and which require other behavioral research methods?

4. Looking at value-added, which existing measures of $21^{\text {st }}$ Century skills are most informative, and what kind of longitudinal, trajectory/pathways data are needed to document the growth of these skills over time?

5. How do we utilize longitudinal and cross-sectional research versus continuous indicators, both for outcomes as well as for contributing factors of the OSU experience? How can we overcome the limitations of correlational analyses between student/alumni outcome and OSU experience data?

6. Could an "exit exam" be designed to measure success trajectories, establish a baseline for longitudinal studies, and provide guidance for actions to improve existing programs at OSU?

7. What institutional and organizational infrastructure is needed to develop an alumni database and survey approach that leads to reasonable response rates?

8. Can the attempt to measure student/alumni long-term success also be used to influence this success?

9. How can we best design research protocols to be mindful of the inherent intervention that surveys and other forms of interactions with alumni introduce into results?

\section{Challenges}

Each group identified some key challenges as the initiative moves forward.

1. Temporality should be addressed; we would need to collect baseline data, and subsequently connected data at critical time points of future student pathways.

2. University personnel at many levels will need to be involved in the research process, which may present capacity issues.

3. There will be many challenges collecting data from students as they leave and continuing to track them for longitudinal research is not trivial, and potentially costly (unless combined with other purposes).

4. Research questions and methods may need adaptations to understand distance, transfer and non-traditional students. 


\section{Next Steps}

The workshop and this resulting report are the first steps toward a well-reasoned and supported research agenda that directly contributes to understanding and measurably improving undergraduate student success at OSU.

The rich discussions during the workshop, and subsequent conversations with key stakeholders within and outside of OSU, point to the need to first establish a guiding theoretical framework. This Framework could be thought of as a logic model that combines in one overarching representation of OSU all the factors identified through both empirical research and the "wisdom of practice" that influence student success and link student success logically with the full set of short- and long-term individual student outcome measures. This step is critical for identifying connections between student experiences and student outcomes. Such a logic model makes visible the various and sometimes diverse factors that influence outcomes, but also reveals where desired outcomes find no equivalent curricular or cocurricular activities that would support achieving the outcome. ${ }^{12}$

The conceptual framework that would emerge from logic modeling would help refine the research questions and overall research agenda, and identify the appropriate methods required to accomplish the indicated research. The research agenda is expected to include the following three major concepts.

- What are the long-term outcomes of a successful undergraduate experience?

- What are the factors, both short and long-term, that contribute to these outcomes?

- What are the roles and responsibilities of OSU faculty and administration for helping achieve these outcomes?

The planning team will likely assemble a transdisciplinary team of methodological and conceptual experts to use the conceptual framework to address the third goal, "to organize the development of a long-term research program at OSU that directly contributes to understanding how to measure and track long-term students success, including key short-term and long-term indicators". These measures will be designed to provide tangible benchmarks and metrics enabling the OSU community to empirically judge both the efficacy of its current efforts as well as guide the design of additional efforts needed to support the student success outcomes.

The Center for Research on Lifelong STEM Learning and the Vice Provost for Student Affairs will work together over the 2014-2015 academic year to facilitate engagement of OSU leadership, garner support for addressing the research agenda, and build partnerships with higher education institutions and associations that may enhance the value of this research under a major OSU initiative to turn the university into a learning laboratory.

\footnotetext{
${ }^{12}$ We are not aware of any attempt so far at other universities at developing such a comprehensive framework for student success. OSU might be breaking new ground in developing such a framework.
} 


\section{APPENDIX I}

Invitation

\section{Redefining Undergraduate Success: an Invitational Workshop April 7, 2014 10:00 a.m. to 2:00 p.m.}

On behalf of a central faculty planning team (below), The Center for Research on Lifelong STEM Learning and the Office of the Associate Provost for Academic Success and Engagement invite you to join a small group of faculty to initiate the design and development of a long-term research program at OSU that will directly contribute to understanding and measurably improving student success. Please direct questions to Julie Risien (julie.risien@oregonstate.edu) and RSVP at http://doodle.com/62a8snmx5eqp8y2y.

We hope to see you there!

The Planning Team:

John Falk, Director of the Center for Lifelong STEM Learning

Susie Brubaker-Cole, Associate Provost for Academic Success and Engagement

Larry Flick, Dean of the College of Education

Jana Bouwma-Gearhart, Associate Professor, College of Education

Kevin Ahern, Professor, College of Science

Julie Risien, Assistant Director, Center for Research in Lifelong STEM Learning

Daniel Newhart, Director of Assessment, Student Affairs

Salvador Castillo, Director of Institutional Research

More Information

Like all colleges and universities, OSU is committed to advancing the success of its undergraduate students. Universities struggle to implement a clear and comprehensive approach to measuring student success. Focus on long-term outcomes like stable and satisfying employment, personal wellbeing, and post-graduation civic engagement and democratic participation are lacking. Most efforts to determine student's success focus on short-term measures such as grade-point average, graduate rate and time-todegree, but there is no clear evidence that these measures correlate with, let alone predict, the kind of desired outcomes suggested above. What should be the definition of student success? Over what timeframe should these outcomes be measured - while at university, immediately following graduation, ten years after graduation or over some longer period? And what factors contribute to these outcomes? Is it sufficient to limit measures to just understanding the role that direct instruction has on student success or is it equally important to also include the roles that participation in academic activities beyond the classroom, participation in non-academic experiences and/or factors that pre- and post-date enrollment at the university have on student success? 
The purpose of this workshop is to convene a group of OSU STEM education scholars and stakeholders to initiate the design and development of a long-term research program at OSU that will directly contribute to understanding and measurably improving student success. At the seminar, an invited group of faculty, researchers and student success stakeholders will engage in an extended, directed discussion to:

a. Operationally define undergraduate success that OSU aspires to, with specific reference to the STEM disciplines;

b. Flowing from the outcomes and parameters of student success defined in Step a, outline a set of key research questions focused on understanding the process and products of current OSU practices; and

c. Begin to organize and support the development of a long-term research program at OSU that directly contributes to understanding how to measure and track long-term students success, including key short-term indicators. These measures will be designed to provide tangible benchmarks and metrics enabling the OSU community to empirically judge both the efficacy of its current efforts as well as guide the design of additional efforts needed to support the student success outcomes define in Step a. 
Re-defining Undergraduate Success Invitational Workshop

Draft Agenda

April 7, 2014 10:00a.m. to 2:00 p.m.

The Depot Meeting Room

700 SW Washington Ave, Corvallis, OR 97330

\section{9:45 Doors Open - Refreshments}

10:00 Introductions and Framing Today's Work

John Falk

10:30 How do We Measure Success?

Presentation and Discussion, Susie Brubaker-Cole and Salvador Castillo

10:45 Public and Political Perceptions of Higher Education

Presentation and Discussion, Martin Storksdieck

11:00 Student Perceptions

Group Discussion, Kevin Ahern

\section{1:25 Elements of Success}

Group Discussion, Julie Risien

11:55 Break

12:05 OSU Aspirational Definition of Success

Group Discussion, Julie Risien

\section{2:30 Lunch}

12:50 Lunch Continued and Developing a Research Agenda

Research Theme Working Groups

\section{1:30 Group Reports}

1:50 Next Steps

John Falk and Susie Brubaker-Cole

\section{2:00 Adjourn}




\section{Participants}

$\begin{array}{ll}\text { Susie Brubaker-Cole } & \text { Academic Affairs (Student Success and Engagement) } \\ \text { Julie Schwartz } & \text { Alumni Programs } \\ \text { Martin Storksdieck } & \text { Center for Research on Lifelong STEM Learning } \\ \text { Julie Risien } & \text { Center for Research on Lifelong STEM Learning } \\ \text { John Falk } & \text { Center for Research on Lifelong STEM Learning } \\ \text { Kay Sagmiller } & \text { Center for Teaching and Learning } \\ \text { Penny Diebel } & \text { College of Agricultural Sciences (AREC) } \\ \text { Felisha Herrera } & \text { College of Education (Adult Education and Leadership) } \\ \text { Larry Flick } & \text { College of Education (Dean) } \\ \text { Jana Bouwma-Gearhart College of Education (STEM) } \\ \text { Lynn Dierking } & \text { College of Education (STEM) } \\ \text { Scott Paja } & \text { College of Engineering (Career and Leadership Development) } \\ \text { Milo Koretsky } & \text { College of Engineering (CBEE) } \\ \text { Christine Kelly } & \text { College of Engineering (CBEE/ Student Affairs) } \\ \text { Teri Duever } & \text { College of Liberal Arts (Advising) } \\ \text { Susana Rivera-Mills } & \text { College of Liberal Arts (Executive Assoc. Dean) } \\ \text { John Edwards } & \text { College of Liberal Arts (Psychological Science) } \\ \text { Lori Cramer } & \text { College of Liberal Arts (Sociology) } \\ \text { Kevin Ahern } & \text { College of Science (Biochemistry) } \\ \text { Indira Rajagopal } & \text { College of Science (Biochemistry) } \\ \text { Julie Greenwood } & \text { College of Science (Biochemistry/ Student Affairs) } \\ \text { Bill Bogley } & \text { College of Science (Mathematics) } \\ \text { Mary Beisiegel } & \text { College of Science (Mathematics) } \\ \text { Barb Taylor } & \text { College of Science (Zoology) } \\ \text { Michele Ribeiro } & \text { Counseling \& Psychological Services } \\ \text { Janet Nishihara } & \text { Educational Opportunities Program } \\ \text { Sally Moore } & \text { Linn-Benton Community College (Developmental Studies) } \\ \text { Jennifer Almquist } & \text { Office of Equity and Inclusion } \\ \text { Salvador Castillo } & \text { Office of Institutional Research } \\ \text { Julie Gess-Newsome } & \text { OsU Cascades (Human Health and Wellness) } \\ \text { Molly Brown } & \text { OSU Foundation } \\ \text { Krista Lane } & \text { OUS International Programs } \\ \text { Ann Schmierer } & \text { Research (Industry Partnering) } \\ \text { LeeAnn Baker } & \text { University Honors College (Advising) } \\ & \end{array}$

